\section{Calculation of Mood's dispersion test statistic using Mielke's adjustment for ties: A program for use on a computer terminal}

\author{
GRANT H. YOUNGMAN \\ Manager of Planning, Federal Reserve' Bank of Atlanta \\ 104 Marietta Street. N.W., Atlanta, Georgia 30303
}

and

WAYNE W. DANIEL

Georgia State University, Department of Quantitative Methods University Plaza, Atlanta, Georgia 30303

Mood (cf. Mood, 1954) has proposed a nonparametric test for equality of dispersion parameters when the data available for analysis consist of observations contained in two independent samples. The test is also described by Conover (1971) and Gibbons (1971). Mood's test is based on the assumptions of symmetric, continuous distributions with equal medians. The test utilizes ranks which are assigned to the observations of the combined samples. The test statistic is based on the sum of squares of the deviations of the ranks assigned to observations of one of the samples from the average of all ranks. The asymptotic relative efficiency of the Mood test relative to the parametric $F$ test is .76 under the assumption of normal populations differing only with respect to their dispersion parameters. Tabies of exact critical values for Mood's dispersion test are available (Laubscher, Steffens, \& De Lange, 1968). The authors also give the normal approximation suitable for use when sample sizes are large. Mielke (1967) has given an exact variance adjustment necessary for the Mood test when ties are present. The adjustment is somewhat involved and the calculations are tedious to perform even on a desk or hand-held calculator. The program described here computes Mood's test statistic for dispersion and applies Mielke's adjustment for ties.
Input. Input to the program is via computer terminal. The data to be entered are the sample sizes $M$ and $N$, where $M<N$, and the observations $X_{1}, X_{2}, \ldots, X_{m}$; $\mathrm{Y}_{1}, \mathrm{Y}_{2}, \ldots, \mathrm{Y}_{\mathrm{n}}$.

Output. The following output is provided: (1) Mood's test statistic, $\mathrm{T}$; (2) the expected value of $\mathrm{T}, \mathrm{E}(\mathrm{T})$; (3) the variance of $T, \operatorname{Var}(T)$; and (4) the large sample (normalized) test statistic:

$$
z=[t-E(T)] / \sqrt{\operatorname{Var}(T)} .
$$

Computer and Language. The program, called MOODST, is written in BASIC and is currently being used on Georgia State University's UNIVAC Series 70/7 computer with input from either an RCA Teletype TY33 or Texas Instrument Silent 700 terminal.

Limitations. The program is limited to 200 data points in the $X$ and $Y$ samples combined. A change in DIM statements of the program ariays will allow larger sample sizes. Documentation furnished in the program listing indicates where changes should be made.

Availability. A program listing is available free from Professor Wayne W. Daniel, Q. M. Department, Georgia State University, University Plaza, Atlanta, Georgia 30303.

\section{REFERENCES}

Conover, W. J., Practical nonparametric statistics. New York: Wiley. 1971. Pp. 234-235.

GiввоNs, J. D. Nonparametric statistical inference. New York: McGraw-Hill, 1971. Pp. 176-179.

Laubscher, N. F., Steffens, F. E., \& De Lange, E. M. Exact critical values for Mood's distribution-free test statistic for dispersion and its normal approximation. Technometrics. 1968, 10, 497-507.

Mielke, P. W., JR. Note on some squared rank tests with existing ties. Technometrics, 1967, 9, 312-314.

Mood, A. M. On the asymptotic efficiency of certain nonparametric two-sample tests. Annals of Mathematical Statistics, 1954, 25, 514-522. 